\title{
Effect of adding prefermented cereal product containing gamma-linolenic acid to broiler feed on production indicators and fatty acid profile of chicken breast
}

\author{
Martin Bača ${ }^{1}$, Slavomír Marcinčák ${ }^{1}$, Milan Čertík ${ }^{2}$, Peter Popelka ${ }^{1}$, Dana Marcinčáková ${ }^{3}$ \\ Lucia Guothová2, Ladislav Molnár ${ }^{4}$, Tatiana Klempová ${ }^{2}$, Iveta Maskal'ová ${ }^{5}$ \\ ${ }^{1}$ University of Veterinary Medicine and Pharmacy in Košice, Department of Food Hygiene and Technology, \\ ${ }^{3}$ Department of Drug and Pharmaceutical Technology, ${ }^{4}$ Clinic of Birds, Exotics and Wildlife, \\ ${ }^{5}$ Institute of Nutrition, Dietetics and Feed Production, Košice, Slovak Republic \\ ${ }^{2}$ Slovak University of Technology, Faculty of Chemical and Food Technology, \\ Department of Biochemical Technology, Bratislava, Slovak Republic
}

Received March 18, 2014

Accepted July 23, 2014

\begin{abstract}
Administration of Thamnidium elegans for effective utilization of agroindustrial materials (wheat bran) creates new perspectives for animal cereal diet enriched with fungal $\gamma$-linolenic acid (GLA). The aim of our study was to evaluate the effect of adding prefermented cereal product containing a high amount of gamma-linolenic acid into the feed on broiler chickens' performance, fatty acids profile and oxidative stability in chilled breast meat. Seventy eight COBB 500 oneday old broiler chicks were randomly divided into 2 treatment groups with three replications and fattened for 42 days. During the first 21 days, all broilers consumed the starter diet. After three weeks, broilers were fed the grower diet; controls were fed without the addition of prefermented cereal product; and the experimental group was supplemented with $3 \%$ of prefermented product. Higher final body weight ( 2688 vs. $2604 \mathrm{~g}$ ) and feed conversion ratio were recorded in the experimental group $(P>0.05)$. The increased GLA content in the experimental diet $\left(0.095 \mathrm{~g} \cdot \mathrm{kg}^{-1}\right)$ resulted in a significant increase of GLA, dihomo-GLA and arachidonic acid in the lipids of breast muscle tissue $(P<0.05)$. Adding prefermented product to the feed also resulted in an increase in total n-3 polyunsaturated fatty acids (PUFA), mainly eicosapentaenoic and docosapentaenoic acid in lipids of breast $(P<0.05)$. The experimental diet produced a significant decrease in the $n-6 / n-3$ ratio (from 10.00 to 8.14 ). Storage of breast muscles with a higher PUFA in chilling conditions led to a decrease in oxidative stability when the values of thiobarbituric acid-reactive substances (TBARS) increased $(P<0.05)$. This is a first study using prefermented cereal product for the fattening of broiler chickens.
\end{abstract}

Biotechnology, chicken, meat quality, PUFA, TBARS

Increased interest in feeds and foods containing a high amount of polyunsaturated fatty acid (PUFA) has been observed because PUFA are considered functional ingredients to prevent coronary heart disease and other chronic diseases (Jung et al. 2010). Poultry production is a potential alternative and sustainable source of PUFA. The current worldwide trend in the production of diets with supplemented components of PUFA has increased the demand for feeds containing $\gamma$-linolenic acid (GLA) for animal nutrition (Laho et al. 2011). Gamma-linolenic acid (C18:3 n-6) via conversion to prostaglandin E1 shows antiinflammatory, antithrombotic, antiproliferative, and lipid-lowering potential (Kaw as hima et al. 2009). However, GLA is rarely found in common foods. Therefore, the interest has been focused on oleaginous microorganisms which enable to accumulate GLA-rich oils in their biomass (Čertík and Shimizu 1999). Solid state fermentations (SSF) have been found as an effective method to naturally enrich various agroindustrial materials with GLA (Čertík et al. 2011). Especially administration of lower filamentous fungi (Zygomycetes) in SSF during utilization of moist solid materials (agriculture by-products) has resulted in low-cost approach for production of valuable metabolites (Čertík et al. 2013). Inexpensive

Address for correspondence:

doc. MVDr. Slavomír Marcinčák, PhD.

Department of Food Hygiene and Technology

University of Veterinary Medicine and Pharmacy in Košice

Komenského 73, 04181 Košice, Slovak Republic

Phone: +421915984756

E-mail: slavomir.marcincak@uvlf.sk

http://actavet.vfu.cz/ 
cereal materials such as rice bran, wheat bran, oat flakes, malted draff, peeled or pearled barley provide a suitable source of nutrients for fungal growth and lipid production.

The advantage of SSF is that these newly formed GLA materials could be used directly for applications such as feed additives (without extraction of GLA oils) to modify the fatty acids profile in poultry (Čertík et al. 2011). Moreover, fungi also simultaneously decrease anti-nutrient compounds and partially hydrolyze substrate biopolymers, which can positively influence the animal production indicators (Čertík et al. 2013).

In this study, the effect of feeding prefermented cereal product enriched with fungal GLA on the production indicators of broilers, fatty acids profile and oxidative stability of broiler breast muscle tissue was described and evaluated for the first time.

\section{Materials and Methods}

The study was carried out using a total of 78 Cobb 500 broiler chickens. One-day-old chicks were randomly divided into 2 groups of 39 birds. Each group had three replicates (13 birds per pen). In all groups, the broiler chickens were fed the same basal diets for 42 days. During the first 21 days, all broilers consumed the starter diet. After 3 weeks, broilers were fed the grower diet; controls without the addition of prefermented cereal product; the experimental group was supplemented with $3 \%$ of prefermented product with a higher content of GLA (3.676 $\pm 1.09 \mathrm{~g} \cdot \mathrm{kg}^{-1}$ in wheat bran; prepared according to Certík et al. [2006]). During the entire fattening period the broiler chickens had free access to water and feed. Temperature and lighting regimes were in accordance with standards for the fattening of broiler chickens (COBB Broiler Management Guide, 2013). The experimental protocol was approved by the Ethics Committee of the University of Veterinary Medicine and Pharmacy in Košice and the State Food and Veterinary

Table 1. Ingredients and nutrient composition of experimental diets.

Administration of the Slovak Republic (No. 12492/10-221).

\begin{tabular}{lccc}
\hline & Starter & \multicolumn{2}{c}{ Grower } \\
Ingredients (\%) & $(1-21)$ & \multicolumn{2}{c}{$(22-42)$} \\
& & Control & Experimental \\
\hline Wheat & 35.00 & 39.20 & 38.02 \\
Maize & 31.00 & 25.80 & 25.03 \\
Soybean meal & 24.50 & 21.50 & 20.86 \\
Sunflower cake & 5.00 & 7.80 & 7.57 \\
Oil & - & 1.95 & 1.89 \\
Limestone & 1.41 & 1.45 & 1.41 \\
Prefermented cereal product & 0.0 & 0.0 & 3.0 \\
Monocalcium phosphate & 1.23 & 1.00 & 0.97 \\
Vitamin-mineral premix* & 0.5 & 0.5 & 0.49 \\
L-lysine & 0.4 & 0.2 & 0.19 \\
NaCl & 0.25 & 0.25 & 0.24 \\
DL-methionine & 0.32 & 0.25 & 0.24 \\
L-threonine & 0.1 & 0.1 & 0.1 \\
\hline Nutrient composition $(\mathrm{g} / \mathrm{kg})$ & \multicolumn{3}{|}{} \\
\hline Metabolized energy (MJ/kg) & 12.3 & 13.15 & 13.44 \\
Crude protein & 200.2 & 191.2 & 210.3 \\
Ash & 70.4 & 69.4 & 63.7 \\
Crude fibre & 38.5 & 39.9 & 41.9 \\
Total fat & 27.6 & 23.0 & 25.7 \\
$\gamma$-linolenic acid (C18:3n-6) & 0.000 & 0.000 & 0.095 \\
& & & \\
\hline
\end{tabular}

*Supplied per kg of basal diet: vitamin A - $12500 \mathrm{IU}$; vitamin D3 - 4 $000 \mathrm{IU}$; vitamin $\mathrm{E}-40 \mathrm{mg}$; vitamin $\mathrm{K} 3-3 \mathrm{mg}$; I $1 \mathrm{mg}$; Co - 0.7 $\mathrm{mg}, \mathrm{K}-8.6 \mathrm{~g} ; \quad \mathrm{Cl}-2 \mathrm{~g} ; \mathrm{Cu}-20.0 \mathrm{mg} ; \mathrm{Fe}-60 \mathrm{mg} ; \mathrm{Zn}-80 \mathrm{mg}$; $\mathrm{Mn}-90 \mathrm{mg}, \mathrm{Se}-0.35 \mathrm{mg}$.

The ingredients and chemical composition of the basal diet are given in Table 1. Values of ingredients content are calculated based on data from the diet supplier. Nutrient compositions of the diets were determined according to standard methods (AOAC 1995). The clinical health status, feed consumption, body weight, and body weight gain of the animals were continuously monitored; the feed conversion ratio (feed intake/ weight gain) was calculated.

On day 42 of fattening the animals were killed by cervical dislocation, and samples were taken. Samples of breast muscles were frozen at $-20{ }^{\circ} \mathrm{C}$ until the time fatty acids analysis was performed. The total fatty acids were extracted from meat samples using chloroformmethanol 2:1 (v/v) based on the method of Folch et al. (1957). Composition of fatty acids was analysed as their methyl esters using gas chromatography (GC-6890 N, Agilent Technologies, USA) with a programmed $60 \mathrm{~m}$ DB-23 capillary column (Agilent Technologies, USA) according to Certík et al. (2006). Samples intended for determination of lipid oxidation in breast meat were vacuum-packed in polyethylene bags and stored in a refrigerator at $4{ }^{\circ} \mathrm{C}$ for 7 days. The amount of thiobarbituric acid reactive substances (TBARS) as an indicator of deterioration of lipids was performed according to Marcinčák et al. (2006) and measured spectrophotometrically 
at $532 \mathrm{~nm}$ (Helios $\gamma$, v. 4.6, Thermo spectronic, UK). Results were quantified as malondialdehyde (MDA) equivalents (mg MDA $/ \mathrm{kg}$ of muscle).

Data were expressed as a mean (x) with standard deviation ( \pm S.D.), followed by one-way analysis of variance with post hoc Duncan's comparison test using GraphPad Software (USA). Treatments were considered significantly different at $P<0.05$.

\section{Results}

Table 2. Effect of diets on production indicators throughout the duration of fattening (42 days).

\begin{tabular}{lcc}
\hline & Control & Experimental \\
\hline Feed intake (g/bird) & $4570.1 \pm 51.2$ & $4560.1 \pm 46.3$ \\
ADFI (g/bird) & $111.5 \pm 3.1$ & $111.2 \pm 2.8$ \\
ADG $(\mathrm{g} /$ bird $)$ & $62.6 \pm 2.5$ & $64.6 \pm 2.2$ \\
Final weight $(\mathrm{g})$ & $2604 \pm 189$ & $2688 \pm 253$ \\
Feed conversion ratio & $1.77 \pm 0.05$ & $1.72 \pm 0.04$ \\
\hline
\end{tabular}

Results are presented as mean \pm S.D., ADFI - Average daily feed intake; $\mathrm{ADG}$ - Average daily gain

The addition of $3 \%$ prefermented product into commercial feed caused an increase of the concentration of total protein, fat, metabolizable energy, and fibre content (Table 1). Higher fibre content is due to the raw material used (wheat bran); higher nutrient content and better digestibility result from the fermentation activity of Thamnidium elegans CCF 1456.

Table 3. Fatty acids composition in lipids of breast meat (\%).

\begin{tabular}{lcc}
\hline Fatty acids (\%) & Control & Experimental \\
\hline Lauric (C14:0) & $0.388 \pm 0.010$ & $0.362 \pm 0.030$ \\
Palmitic (C16:0) & $22.149 \pm 0.361$ & $21.467 \pm 0.421$ \\
Plamitoleic (C 16:1n-7) & $3.643 \pm 0.330$ & $2.997 \pm 1.020$ \\
Stearic (C18:0) & $12.439 \pm 1.460$ & $12.632 \pm 2.50$ \\
Oleic (C18:1n-9) & $27.381 \pm 2.350$ & $25.692 \pm 2.56$ \\
Vaccenic (C 18:1n-7) & $2.396 \pm 0.200^{\mathrm{b}}$ & $2.957 \pm 0.106^{\mathrm{a}}$ \\
Linoleic (C18:2n-6) & $20.567 \pm 0.360$ & $19.717 \pm 0.672$ \\
$\gamma$-linolenic (C18:3-6n-6) & $0.132 \pm 0.020^{\mathrm{b}}$ & $0.190 \pm 0.014^{\mathrm{a}}$ \\
$\alpha$-linolenic (C18:3n-3) & $1.182 \pm 0.250$ & $1.180 \pm 0.180$ \\
Eicosenoic (C20:1n-9) & $0.337 \pm 0.020$ & $0.377 \pm 0.030$ \\
Eicosadienoic (C20:2n-6) & $0.702 \pm 0.140^{\mathrm{b}}$ & $0.841 \pm 0.060^{\mathrm{a}}$ \\
Dihomo- $\gamma$-linolenic (C20:3n-6) & $0.681 \pm 0.180^{\mathrm{b}}$ & $1.139 \pm 0.190^{\mathrm{a}}$ \\
Arachidonic (C20:4n-6) & $2.913 \pm 0.53^{\mathrm{b}}$ & $4.356 \pm 0.610^{\mathrm{a}}$ \\
Eicosatrienoic (C20:3n-3) & $0.104 \pm 0.080$ & $0.130 \pm 0.060$ \\
Eicosatetraenoic (C20:4n-3) & $0.069 \pm 0.010^{\mathrm{b}}$ & $0.138 \pm 0.074^{\mathrm{a}}$ \\
Eicosapentaenoic (C20:5n-3) & $0.208 \pm 0.020^{\mathrm{b}}$ & $0.386 \pm 0.090^{\mathrm{a}}$ \\
Docosapentaenoic (C22:5n-3) & $0.521 \pm 0.180^{\mathrm{b}}$ & $0.776 \pm 0.253^{\mathrm{a}}$ \\
Docosahexaenoic (C22:6n-3) & $0.446 \pm 0.020$ & $0.544 \pm 0.142$ \\
$\sum$ SFA & $37.253 \pm 1.530$ & $37.775 \pm 2.960$ \\
$\sum$ MUFA & $33.782 \pm 2.961$ & $32.022 \pm 3.670$ \\
$\sum$ PUFA n-3 & $2.598 \pm 0.096^{\mathrm{b}}$ & $3.254 \pm 0.014^{\mathrm{a}}$ \\
$\sum$ PUFA n-6 & $25.984 \pm 0.570$ & $26.500 \pm 0.520$ \\
$\sum$ PUFA & $28.966 \pm 0.522$ & $30.203 \pm 1.221$ \\
n-6/n-3 ratio & $10.00 \pm 0.50^{\mathrm{b}}$ & $8.14 \pm 0.43^{\mathrm{a}}$ \\
\hline Resilts a presen & &
\end{tabular}

Results are presented as mean \pm S.D., SFA - saturated fatty acids, MUFA - monounsaturated fatty acids, PUFA polyunsaturated fatty acids, ${ }^{\mathrm{a}, \mathrm{b}}$ - significant difference $(P<0.05)$. 
Results of the effect of adding 3\% prefermented cereal product to the diet on the production indicators are presented in Table 2 . Higher final weight, improved daily gain and feed conversion were observed in the experimental group $(P>0.05)$. Food consumption was not affected by the addition of prefermented product and was comparable to the control $(P>0.05)$.

Fatty acid profile of breast muscles in both groups is given in Table 3 . In the experimental group increased proportion of n-3 PUFA was found in fat of breast muscle, and the ratio n-6/n-3 PUFA was significantly lower $(P<0.05)$. Compared to control, $1.5 \times$ higher content of GLA, dihomo-gamma-linolenic and arachidonic acid was determined in the experimental group $(P<0.05)$. In the experimental group the vaccenic acid content increased by $23.41 \%$, GLA content by $43.94 \%$, and eicosadienoic acid content by $19.80 \%$. Of much importance is also a higher proportion of n-3 PUFAs (eicoasapentaenoic - 100\%, docosapentaenoic $85.58 \%$ acids, $\sum$ PUFA $n-3-25.25 \%$ ) in the experimental group.

Table 4. Effect of diets on thiobarbituric acid reactive substances (TBARS) in breast meat tissues stored in chilling conditions $\left(4^{\circ} \mathrm{C}, 7\right.$ days $)$.

\begin{tabular}{lccc}
\hline \multirow{2}{*}{ Diet } & \multicolumn{3}{c}{ TBARS $\left(\mathrm{mg} \cdot \mathrm{kg}^{-1}\right)$} \\
\cline { 2 - 4 } & Day 1 & Day 4 & Day 7 \\
\hline Control & $0.137 \pm 0.040^{\mathrm{aA}}$ & $0.139 \pm 0.03^{\mathrm{aB}}$ & $0.276 \pm 0.03^{\mathrm{aC}}$ \\
Experimental & $0.197 \pm 0.032^{\mathrm{bA}}$ & $0.331 \pm 0.05^{\mathrm{bB}}$ & $0.380 \pm 0.08^{\mathrm{bC}}$ \\
\hline
\end{tabular}

Results are presented as mean $\pm \mathrm{SD}$, a, b - values in a column sharing different letters are significantly different $(P<0.05),{ }^{\mathrm{A}, \mathrm{B}, \mathrm{C}}-$ values within rows sharing

Results of the effect of adding 3\% prefermented cereal product to the diet on oxidation stability during chilling storage are presented in Table 4 . The oxidative stability of breast muscles was affected by adding 3\% prefermented cereal product to the diet when concentration of TBARS was found to be increased $(P<0.05)$ compared to control. Higher content of PUFA, mainly eicoasapentaenoic acid (EPA), docosapentaenoic acid (DPA) and arachidonic acid in the experimental group was manifested by lower oxidative stability of meat during the entire period of storage in the refrigerator.

\section{Discussion}

Nutritional strategies for enrichment of poultry meat with PUFA, based primarily on the use of linseed oil or other plant oils and fish oil have been developed and designed. However, beside the positive impact on the fatty acid profile, some negative effects on growth indicators (lower gains, final weight, decreased feed conversion) appeared due to the antinutritive substances in these oil-rich plants (Aziza et al. 2010). During solid state fermentation the fungus Thamnidium elegans produces enzymes necessary for hydrolysis of sources bound in biopolymers. Thus the fungal hyphae rapidly penetrate the substrates (wheat bran) resulting in their efficient consumption. Fungi also decrease amounts of antinutritive compounds in the final prefermented product (Čertík et al. 2013). This study has demonstrated that the prefermented cereal product exerted a positive effect on production indicators of chicken. In the experimental group, its administration resulted in increased performance and feed conversion ratio. Since this is the first study evaluating the effect of administrating a product prefermented by Thamnidium elegans enriched with GLA in poultry fattening, it is impossible to compare its results with other authors. However, the indicated results confirm a positive effect of the feed. 
The prefermented cereal product increased the content of GLA in lipids of produced chicken breasts. A higher proportion of GLA probably elevated the content of dihomoGLA and arachidonic acid (AA). Particularly significant increase of dihomo-GLA was determined, because this essential fatty acid was found in animal products only in trace amounts (Kawashima et al. 2009). Analysis of the fatty acid profile in poultry meat have also shown that the administration of $3 \%$ prefermented product significantly increased the proportion of n-3 PUFA, particularly EPA and DPA, and the ratio n-6/n-3 PUFAs was reduced. Significant reduction of the ratio due to the use of the organic product is not anticipated, since the prefermented product provides a feed with higher concentrations of n-6 fatty acids. However, although the ratio of n-6/n-3 PUFAs was reduced in chicken fed the prefermented product, the total amount of n- 6 fatty acids was enhanced. Especially, total level of essential GLA, dihomo-gamma-linolenic acid and arachidonic acid in chicken meat fed the prefermented product was $1.5 \times$ higher compared to control. This most important finding indicates that GLA supplemented in feed could stimulate biosynthesis of C20 n-6 PUFAs in chicken meat. From this point of view, this is the first study that has confirmed effectiveness of administration of GLA-rich feed in chicken. Similar studies carried out with $5 \%$ and $10 \%$ addition of prefermented GLA-cereals to the chicken feed are the subject of forthcoming experiments.

There was a significantly lower oxidative stability of the meat from broilers fed the prefermented feed product compared to broilers fed the control diet. The significantly lower oxidative stability of the meat from broilers fed the prefermented cereal product compared to broilers fed the control diet was probably due to a higher content of PUFA in lipids of meat tissues. Many studies linked oxidative instability in meat and meat products with increasing concentrations of PUFA (Guillevic et al. 2009; Betti et al. 2009). Unsaturated lipids readily undergo oxidation to produce peroxides and aldehydes, which are responsible for the reduction in storage quality that is often associated with poultry meat with an enhanced PUFA content (Betti et al. 2009). Although TBARS values in the experimental group were significantly higher compared to control even on day 7 of storage under chilling conditions, in the experimental group such values were not observed $\left(0.380 \mathrm{mg} \cdot \mathrm{kg}^{-1}\right)$, which would have a significant impact on the quality of the meat. It is also required to use a sufficient amount of antioxidants for better protection of meat against oxidative damage of lipids (Marcinčák et al. 2011; Kralik et al. 2013).

Supplementation of the prefermented cereal product to broiler diet was efficient because the increase of broiler performance, feed conversion ratio and increase in portions of GLA, dihomo-GLA, arachidonic acid and total n-3 PUFAs in breast muscle was positively influenced. Even though meat oxidation stability was lower, TBARS values were not high enough to affect the quality of produced meat.

\section{Acknowledgments}

This study was supported by the Ministry of Education of the Slovak Republic (Projects VEGA No. 1/0648/11, 1/0975/12, and 1/0457/14) and by the Slovak Research and Development Agency (Grant APVV-0662-11).

\section{References}

AOAC 1995: Official Methods of Analysis, $16^{\text {th }}$ ed. Association of Official Analytical Chemists, Arlington, VA, USA

Aziza AE, Quezada N, Cherian G, 2010: Antioxidative effect of dietary Camelina meal in fresh, stored, or cooked broiler chicken meat. Poult Sci 89: 2711-2718

Betti M, Schneider BL, Wismer WV, Carney VL, Zuidhof MJ, Renema RA 2009: Omega-3-enriched broiler meat: 2. Functional properties, oxidative stability, and consumer acceptance. Poultry Sci 88:1085-1095

COBB Broiler Management Guide, 2013. Available at: http://cobb-vantress.com. Last modified November 15, 2013. Accessed December 7, 2013 
Čertík M, Shimizu S 1999: Biosynthesis and regulation of microbial polyunsaturated fatty acid production - a review. J Biosci Bioeng 87: 1-14

Čertík M, Slavikova L, Masrnova S, Sajbidor J 2006: Enhancement of nutritional value of cereals with $\gamma$-linolenic acid by fungal solid state fermentations. Food Technol Biotechnol 44: 75-82

Čertik M, Adamechova Z, Laoteng K 2011: Microbial production of gamalinolenic acid: submerged versus solidstate fermentations. Food Sci Biotechnol 21: 921-926

Čertík M, Klempová T, Guothová L, Mihálik D, Kraic J 2013: Biotechnology for the functional improvement of cereal-based materials enriched with polyunsaturated fatty acids and pigments. Eur J Lipid Sci Technol 115: 1247-1256

Folch J, Lees M, Stanley GHS 1957: A simple method for the isolation and purification of total lipids from animal tissues. J Biol Chem 226: 497-509

Guillevic M, Kouba M, Mourot J 2009: Effect of a linseed diet on lipid composition, lipid peroxidation and consumer evaluation of French fresh and cooked pork meats. Meat Sci 81: 612-618

Jung S, Choe JH, Kim B, Yun H, Kruk Z, Jo Ch 2010: Effect of dietary mixture of gallic acid and linoleic acid on antioxidative potential and quality of breast meat from broilers. Meat Sci 86: 520-526

Kawashima H, Toyoda-Ono Y, Suwa Y, Kiso Y 2009: Subchronic (13 week) oral toxicity study of dihomo- $\gamma-$ linolenic acid (DGLA) oil in rats. Food Chem Toxicol 47: 1280-1286

Kralik Z, Kralik G, Biazik E, Straková E, Suchý P 2013: Effects of organic selenium in broiler feed on the content of selenium and fatty acid profile in lipids of thigh muscle tissue. Acta Vet Brno 82: 277-282

Laho T, Varadyova Z, Mihalikova K, Kisidayova S, Adamechova Z, Certik M, Jalc D 2011: Prefermented cereals containing fungal gamma-linolenic acid and their effect on rumen metabolism in vitro. Czech J Anim Sci 56: 325-335

Marcinčák S, Popelka P, Zdolec N, Mártonová M, Šimková J, Marcinčáková D 2011: Effect of supplementation of phytogenic feed additives on performance parameters and meat quality of broiler chickens. Slov Vet Res 48: 27-34

Marcinčák S, Sokol J, Turek P, Popelka P, Nagy J 2006: Determination of MDA in pork meat using solid phase extraction and HPLC. Chem Listy 100: 528-532 